\author{
ANNA STWORA \\ ORCID: 0000-0002-1134-1092 \\ Instytut Językoznawstwa \\ Uniwersytet Śląski w Katowicach \\ Wydział Studiów Europejskich, Amerykańskich i Międzykulturowych \\ Uniwersytet Sapienza w Rzymie
}

\title{
Simplicity for humorous purposes? On minimalistic yet humorous multimodal press ads
}

\section{Summary}

This paper aims to explore the instances of minimalistic multimodal press ads in order to show that, in spite of their relative simplicity, they can be used effectively for humorous purposes. The author starts her discussion with some general remarks on multimodality and then clarifies the notion of minimalism, setting it in the realm of advertising discourse. Subsequently, she offers a brief overview of the incongruity-resolution theory of humour, providing the reader with basic knowledge of the mechanisms of humour. Finally, based on a selection of minimalistic press ads which subscribe to the said theory of humour, the author performs a qualitative content analysis thereof, the results of which indicate that simplicity by no means renders advertising discourse plain. On the contrary, it helps the audience to focus on the gist, as well as to appreciate the creativity and humorous wit of minimalism in ads.

Keywords: minimalistic advertising, humour studies, advertising discourse, simple language.

\section{Introduction}

It is an axiom that advertising discourse ${ }^{1}$ rests heavily upon visual communication that has made it possible for ads to become more complex, stunning, and flashy. The spectacular growth of modern technologies by means of which ads are produced and disseminated has led to a situation in which "quantity underpins contemporary existence" (Botha 2015: 745). It has also led to the creation of imaginative messages

${ }^{1}$ Understood as the assemblage of means of expression deployed within the advertising genre or, in other words, as an extensive range of linguistic and non-linguistic techniques used by advertisers for promotional communication. 
that co-deploy the textual and the visual mode or merge several images into impossible pictures, thus making it possible for advertisers to deliver their messages in a multitude of creative ways. Such innovative creations surely merit discussion, but so do simpler, more minimalistic ads whose impact can be as profound as that of complex advertising messages, the sheer abundance of which may at times seem overwhelming to the audience.

In fact, simple language has come to be perceived as a strong communication strategy that stands out from the information clutter thanks to simplicity itself. It is argued that "volume and complexity [...] no longer command consumer attention the way they once did, posing a serious problem for businesses struggling for market share. Minimalism in advertising offers one potential answer to this problem" (Dontigney 2019). This paper therefore seeks to explore several selected instances of minimalistic multimodal press ads with a view to showing that minimalistic advertising messages can be used effectively for humorous purposes, despite their relative simplicity. To this end, the author will conduct a qualitative content analysis of selected minimalistic press ads retrieved from the website www.adsoftheworld.com, with constitutes an extensive archive of advertising messages.

\section{A few words on multimodality}

The shift in favour of the pictorial component in advertising is the main pillar of press advertising and visual consumption that is extremely persuasive, owing to "its ability to photographically frame and redefine [...] meaning and [...] experience" (Kumar 2008: 37). This is due to the fact that the pictorial is self-explanatory and easy to ingest, which, in turn, renders it so appealing. The increased focus on visual and multimodal representation, along with the more and more subordinate role of the verbal component, is "[...] by no means damaging to the quality of the message transmitted; on the contrary, visual ads are perceived as particularly evocative rhetorical constructs [...] due to the multilayered nature of meaning they carry" (Stwora 2019: 57).

At the outset, one should devote a few lines to the definition of multimodality that is concerned with "the interaction and combination of multiple modes within single artefacts" (Bateman 2008: 1). In other words, it takes into consideration each and every modality that is responsible for the creation of the message, as well as the relations between these modalities and additional meanings that stem from these relations (Maćkiewicz 2017: 34). Multimodality presumes that there is a complicated dialogical interplay between the text and image within one message (Karaśkiewicz 2013); the textual is decentralised as a main meaning-carrier, and the "traditional" boundaries between the roles played by the modalities involved are redrawn (Kawka 2016: 295). As a result, "[...] the linguistic and pictorial are used simultaneously to convey a message and construct composite meanings (Tanaka 1996). Thus, one 
no longer deals with singular semiotic modes but rather with two modes combined, moving between various layers of an ad" (Stwora 2019: 60).

What follows from the above-mentioned is that the textual and the visual are treated as equal forms of expression that "point to particular interpretations of experience and forms of social interaction" (Kress, van Leeuven 1996: 2) on which culture, cognition, and communication pivot. As posited by these authors, it is due to the fact that meanings actually belong to cultural practice and not to specific semiotic modes (cf. Kress, van Leeuven 1996). This means that multimodal advertising makes use of a common pool of concepts expressed in part thanks to images and partly through the textual. All in all, the role of the image nowadays is to capture the prospects' attention and convey meanings in a more straightforward manner, whereas that of the text is to steer their interpretation towards the one intended by the advertiser.

Creating a minimalistic multimodal ad, however, seems to present more difficulties since their constitutive elements require careful thought. The presence of too many elements will inevitably destroy the appeal of simplicity and hence bury the cutting edge; yet, too simplified an ad may turn out to be incomprehensible to the audience, thus falling short of the mark. That is why, as far as the rhetoric of the image is concerned, simplicity in ads is seen as sophistication that "is tied to upscale taste" (Berger 2011: 19) and, likewise, requires meticulous attention on the part of their creators.

\section{Minimalism in advertising}

"Minimalism is a dynamic movement that relates to a number of fields. [...] As a style, it involves simple design formats (Burgess 1997), sparseness (Botha 2015; Inbar, Tractinsky, and Meyer 2007), and visual peace (Stevanovich 2013)" (Margariti et al. 2017: 1). In this context, simplicity should be understood as a rhetorical, stylistic, and aesthetic category that, in general terms, favours uncomplicated forms over complex ones. This is usually achieved by means of large monochrome spaces (Margariti et al. 2017) and reduced pictorial and textual content (Stöckl 2009) that convey the idea of the aforementioned visual peace (Stevanovich 2013). At first glance, it may seem that a simpler design means something plain, basic, and inconspicuous that, consequently, would not attract attention. Nonetheless, simple advertising messages often require much more brainpower to both encode and decode.

First of all, it is difficult to keep an ad concise and entirely transparent, thus limiting any potential perceptual distraction, and retain its full communicative potential at the same time. The key issue is hence to make use of "limited material in order to create the desired effect" (VanEenoo 2011: 7). From the recipient's perspective, on the other hand, such a reductive advertising strategy (Margariti et al. 2017) that eschews excess makes the audience ponder over the message and "[...] put the 
finishing touches in the incomplete elements (Abadi-Nagy 2001)" (Margariti et al. 2017: 1). Consequently, the recipient's inferences and associations assume control of the comprehension process, steering him towards the intended meaning.

It is actually striking when one comes to realise that something very simple may be capable of conveying so much more than expected. That is why minimalistic ads often prove truly memorable and hit the nail right on the head, so to speak. Usually, they effectively command the audience's attention and draw it towards the key element that is central to the ad (Dontigney 2019). Nevertheless, one should also remember that minimalist aesthetic should not be perceived as a universal and miraculous strategic tool because some messages may become too difficult to understand if simplified too much.

\section{The mechanisms of humour}

"Contemporary advertising not only tries to inform, but also transform, offering joy and pleasure to its recipients (O'Donohoe 2001). This transition implies differences in the communication style and information itself" (Margariti et al. 2017: 3-4), which means going for the jocular and infotainment instead of straightforward claims. Minimalist aesthetic characterised by the broadly conceived quality of simplicity (Inbar, Tractinsky, Meyer 2007), however, does not preclude humour since funniness does not stem from complexity, but rather from an incongruity, usually understood as "a comic collision of or oscillation between two frames of reference/worlds of discourse/codes/associative contexts" (Krikmann 2009: 17). Once the perceiver encounters such an incongruity, his conceptual system is violated, as the incongruous element departs from his relevant cognitive model of reference (Dynel 2013: 27). Although much more could be said about the incongruity-resolution pattern, it is beyond the ambit of this paper. That is why the author will try to provide the shortest possible description thereof:

In brief, the two-stage incongruity-resolution model assumes that the humour respondent typically has expectations about the verbal or pictorial material to which he is attending. The humour stimulus is deliberately constructed to play-off these expectations and thus generates incongruity. After this stage has occurred, the respondent is motivated to resolve or make sense of the incongruity (Suls 1976: 41).

It is traditionally accepted in humour studies to speak of incongruities in terms of script opposition (hereinafter referred to as SO) (Raskin 1985), with the script (or scenario) defined as a "large chunk of semantic information surrounding the word and evoked by it [...]" (Raskin 1985: 46). Consequently, if scripts refer to rudimentary, common mental representations of particular situations, their oppositions necessarily violate these representations, which results in an incongruity that should be resolved for the perceiver to understand the humorous message. Thus, 
in order to engender humour, the pairs of scripts need to be in a relationship of opposition; according to Raskin, these may generally fall into three classes, namely: actual/non-actual, normal/abnormal, and possible/impossible SOs (Raskin 1985: 111). Nonetheless, this does not mean that other types of SOs are impossible, for one may also deal with the good/bad, light/dark or high/low SO, to name but a few.

The oppositeness of one scenario to another, however, is a rather vague criterion laid down to approximate the phenomenon of humour; while it is impossible to gainsay Raskin and his Script-based Semantic Theory of Humour, many researchers in the field pointed out to the fact that mere contrasts do not conduce to humour on all occasions. That is why some scholars proposed that the semantic distance between the two concepts entering the incongruous pairing could be measured in terms of (non) prototypicality relations (Chen, Jiang 2018; Giora 1991; Nerhardt 1976). According to this line of reasoning, "multimodal humour can be built on: (1) prototypicality and non-prototypicality of category members; (2) the family resemblance shared by category members; and (3) the fuzzy inter-categorical boundary" (Chen, Jiang 2018: 74).

Because of the fact that interaction with the world requires of the perceivers to rely on typical, schematised, and already-experienced patterns of behaviour and reasoning, they refer to cognitive frames, schemas, and scripts in order to store the acquired knowledge and apply it in other situations so as to avoid too much cognitive effort. Human perception may hence be seen as "categorial internal structuring which differentiates between the cognitive status of the prototype (the unmarked member) and the marginal status of the marked member" (Giora 1991: 465), which refer to what people expect to occur and to what they find less likely to happen, respectively. If a stimulus is to be categorised as humorous, it therefore needs a perfect balance between the two for a pronounced incongruity to emerge; put differently, the opposing script needs to belong to "the class when perceived in its entirety" (Nerhardt 1976: 50) and, also, to "diverge in several uni-dimensional qualities from the typical elements in the class" (Nerhardt 1976: 50). In this context, and despite its possible shortcomings, to date, the prototype theory seems to best capture the distance between the scenarios involved.

\section{Selected minimalistic humorous ads - a qualitative analysis}

Humorous discourse may take many forms since humour cuts through various genres and types of discourse (Chłopicki, Brzozowska 2017), including advertising. The aim of this paper is to test the humorous potential of the "less is more" philosophy on the selected examples of multimodal press ads in English retrieved from the advertising database www.adsoftheworld.com. Although such researchers as, for instance, Margariti et al. (2017) provide a more detailed typology of minimalist advertisements, subdividing such constitutive elements as space, image, and text into 
further categories pertinent to, e.g. the actual colours used, the geometry of images or font type and size, the present study will not be that detailed and will be concerned with broadly conceived visual simplicity characterised by:

a) large monochrome space (Margariti et al. 2017),

b) reduced pictorial and textual content (Stöckl 2009),

c) the effect of visual peace (Stevanovich 2013).

The qualitative research was originally conducted on a corpus of 30 ads created between 2007 and 2015 that, unfortunately, could not be presented and described herein in full detail due to conciseness. The author decided to limit herself to presenting several exemplary ads that, upon conducting qualitative content analysis, could be discussed as paragons of simplicity for humorous purposes. Apart from their simple form, the minimalistic yet humorous multimodal press ads chosen for this paper apply incongruity-resolution-based humour, whose workings will be explained in the lines to follow. It was decided that the ads be presented in alphabetical order.

To begin with, the ad promoting Bayer Aspirin presents the audience with a question written in black capital letters on a white background, which is supposed to convey the idea of visual peace (Stevanovich 2013) since "white space is considered to be a conspicuous, non-pictorial, visual trope that highlights absence rather than presence" (Margariti et al. 2017: 4). However, this apparent peacefulness is broken by the textual layer that reads: "Dad, can I borrow some money?". There are two possible options provided as to who the addressor of this question is; the first one is in green font and says: "your 15-year old son" and is accompanied by a very small picture of Aspirin, whereas the other one uses red font to suggest that the person asking this question is "your 45-year old son" (this answer is placed next to a small representation of a stronger version of the painkiller, CafiAspirin). Such a colour-coding strategy is actually deeply meaningful because green is used to elicit positive feelings of relaxation and calmness (Tornetta, Fox, Blackbird 2009), here standing for the normal state of affairs, while the red colour is applied to express alarm over your adult child wanting money from you. As a result, one deals with the normal/ abnormal SO and, more specifically, with the good/bad or safety/danger SOs associated with the situation in which a child and an adult ask for money, respectively. In this case, one can identify multimodal humour that is built on prototypicality versus non-prototypicality of category members, for " [...] one of the modalities alludes to a category whose prototype/non-prototype is presupposed while another modality presents the opposite" (Chen, Jiang 2018: 76). Upon seeing the caption, one automatically thinks of a child that actually may be in need of funds, as he cannot earn it on his own yet. The option "your 45-year old son," however, shatters any preconceived assumptions the audience may have held about the situation, thus leading to a humorous clash of scripts.

Next is the ad for Bank Forum, Commerzbank, entitled "Chaos". It shows a plain, light bluish background, whose colour is designed to convey the sense of comfort 
and peace to the audience (Tornetta, Fox, Blackbird 2009). It the foreground, one can see a neat row of paper clips, one of which is turned upside down, thus causing chaos in German style, as suggested by the slogan ("Chaos. German style."). It serves to reduce the idea of Germanness to the core idea of orderliness that stands in stark contrast to the notion of chaos evoked by the ad. It may also be interpreted as an attempt at communicating that banking in German style by Commerzbank means not only orderliness, but also the ability to think outside the box in certain situations. It therefore turns out that reduced pictorial and textual content can actually convey complex information that, apart from being simple and accessible, is also humorous, as it makes use of the actual/non-actual and order/chaos SOs that create an air of humour. As in the previous example, humour is based on the clash between prototypicality and non-prototypicality of category members because the domain of chaos implies madness, disorganisation, and confusion, whereas the one of Germanness, on the other hand, remains non-prototypical since it is associated with order. Thus, because of the fact that the latter notion is seen as less central to the concept of chaos, it engenders humour quite effectively, as it leads to "a comic collision of [...] associative contexts" (Krikmann 2009: 17).

Another interesting minimalistic ad is the one for Bosch - it shows a fly whose leg has got stuck under a screw that has just been screwed into a piece of wood, thus trapping the insect for good. The bottom part of the ad provides an explanation, as it presents the audience with Bosch's logo, a little picture of a drill, and a telling caption "It's faster than you think: the PSR 14.4 LI-2 cordless screwdriver". The ad therefore makes use of the possible/impossible and fast/slow SOs so as to convey that their product is extremely fast and efficient, to the fly's dismay. Despite the reduced amount of information conveyed, the perceiver is capable of unpacking the more complex senses which are accessible to people in general, thanks to the common pool of meanings they share as the users of a the same language and as members of a given culture who share a similar contextual environment. Therefore, because of the fact that, based on his experience, the perceiver normally associates flies with a nuisance that is too fast to catch, the mere sight of a fly caught by a fast electric drill seems surprising. Although the prototypical feature of the two domains involved is one of speed, it is the fly that is thought to be faster, which is why the ad successfully violates any previous expectations the audience may have had, thus resulting in an incongruity that is responsible for the production of humour. Again, humour is based on prototypicality versus non-prototypicality of category members, with the shared category being that of fast-moving objects.

The same mechanism is present in the ad promoting Gomby chewing gum, that plays with homonymous words sweet and sour that may be used to address both taste and disposition. The ad is clearly divided into two colour-coded parts and consists of one sentence that is also split into two parts. The sentence starts on a red background and reads: "I love you," while the other part, that is set against the yellow one, continues the sentence: "like I love a Monday morning". Obviously enough, 
"I love you" markedly differs from "I love you like I love a Monday morning", so one automatically comes to the conclusion that the speaker does not like his interlocutor at all, for no one loves Mondays. Because the ad evolves in a direction that was unexpected by the audience, as what seemed to be a love confession turns out to be an ironic quip, a comic oscillation between two completely different frames of reference (Krikmann 2009) is unavoidable. There is yet one important dimension to this ad, for the colour-coding strategy presents the audience with two types of chewing gums, the sweet and the sour, whose small representations are included under the "I love you" and "like I love a Monday morning" parts, respectively. It therefore suggests that Gomby chewing gum is perfect for every occasion because whether you decide to be lovable or mean, there is always a taste that suits the mood. It is impressive that such a meaning-laden ad could be skilfully reduced to one sentence that, coupled with the visual layer, communicates so many SOs at the same time (the normal/abnormal, liking/disliking, sweet/sour, and nice/mean SOs). As far as its design is concerned, keeping the ad short and simple gives it a modern, minimalist look whose main focus is on "geometric shapes, lines, and the relationship between [...] space" (Dontigney 2019) and colouring, which makes it very eye-catching.

The following print ad for Hut Weber (German hatters) is particularly evocative because it adheres to the rule of reduced pictorial and textual content (Stöckl 2009) in a very creative and thought-provoking way. An old sheet of paper is used as the background for two geometric figures whose shapes make one think of Hitler and Chaplin's hairstyle and moustache, the only difference between the two being a bowler hat on the head of the latter. The caption simply reads: "It's the hat," therefore suggesting that it is the product advertised, i.e. the hat, that may change one's appearance and make it better. Discussing the very same ad, Macleod (2008) cites Charlie Chaplin himself who was supposed to say: "Life is a tragedy when seen in close-up, but a comedy in long-shot". It seems that the advertising agency responsible for this ad was actually of a similar opinion; the very fact that the ad was produced in Germany makes it even more interesting, as it testifies to the advertiser's ability to distance himself from history and make it a part of a humorous creation. Nonetheless, since such an advertisement still constitutes a highly polarising act of humour, "the advertising campaign inevitably raised the ire of many Germans who firmly believe that Hitler should never be associated with any kind of advertising" (Macleod 2008). Appropriateness aside, when it comes to the formal features of humour present in this ad, one may identify several SOs, starting from the very basic bad/good SO and ending with the terror/entertainment or war/peace SO. As opposed to the examples discussed beforehand, the ad for Hut Weber is an instance of multimodal humour based on family resemblance (understood in terms of prototype theory) that, in this case, is founded upon the strong similarity between the figures presented. Although the two individual category members involved in this comparison for similarity remain very distinct entities of a recognisably different nature, "the distinction is deliberately disregarded and category members are seen 
as more or less the same" (Chen, Jiang 2018: 77). Thus, family resemblance resultant from a similar hairstyle and moustache is highlighted instead of the fact that Hitler and Chaplin are fundamentally distinct entities. This, in turn, inevitably leads to a perceptual incongruity that engenders humour.

The last, and perhaps the wittiest example to be analysed here, is the ad for the KISS FM radio station, whose "brevity and simplicity [...] contrast with the excitement and visual richness" (Berger 2011: 177) expressed through the vivid red background and a black compact cassette. The first thing that comes to one's mind is that the compact cassette is supposed to refer the audience to the times of analogue audio associated with the old hits featured by the said radio station. The message is far more complex, however, as it also uses a slogan: "iPod... I am your father" that is an explicit reference to the fifth episode of the Star Wars saga. In The Empire Strikes Back, after the final lightsaber duel between the hero of the Rebel Alliance, Luke Skywalker, and the greatest villain of the Galactic Empire, Darth Vader, the latter tells the former: "Luke... I am your father". In this pop-cultural context, one can clearly see that the slogan invests the advertising message with a new, richer, metaphorical, and simultaneously humorous meaning. Given the fact that it is necessary to situate the ad in a wider context, multiple SOs emerge, thus rendering the ad very interesting and appealing; to be more specific, one deals with the actual/non-actual, the real/imaginary, and the old/new SO, as well as with the good/bad and dark/light SO. All in all, humour in the ad under consideration is based on what Chen and Jiang (2018) label as the fuzzy inter-categorical boundary, whose common features are actually captured by the dichotomy between light and dark, between what is good and bad, as well as between what is old and new.

\section{Closing remarks}

Good design choices should immediately capture the prospect's attention, surprise and provoke emotions; at the same time, they should be simple and understandable enough for the audience to feel that they actually understood the message (Bergström 2009: 88). Minimalist ads for humorous purposes are just like that, which was shown on the basis of several examples that illustrate the "less is more" philosophy. The present paper employed qualitative content analysis with a view to exploring selected instances of humorous minimalist print advertisements; thanks to the insights gained from the incongruity-resolution theory of humour and the prototype-theoretical perspective, it was explained why the ads selected for the purpose of this paper were humorous, albeit very simple. It turned out that simplicity did not cause the ads discussed to devolve into one-dimensional, dull, and uninspiring messages, but rather emphasised their essence, evocativeness, and wit.

It was argued that simplicity is an important dimension of advertising communication due to the fact that minimalism does not preclude humour or originality 
in any way. Likewise, "conceptual complexity is not directly linked to the density of multimodal cues in an advertisement. In fact, minimalist advertisements, if wittily devised, are ideal candidates to trigger conceptual operations in multiple directions" (Pérez-Sobrino 2017: 105), which testifies to their evocativeness. Sometimes the simplest advertisement is capable of conveying the strongest message, for uncomplicated forms can command attention effectively, freeing themselves from information clutter and thus helping the audience to focus on the gist. If too many competing visual and textual elements are crammed into one ad, one risks the creation of visual or informational noise the perceiver may get tired of, hence abandoning his attempt to actually understand the message (Dontigney 2019). Minimalism in advertising, on the other hand, offers visual peace and a simple form that "aims to strip out virtually all the visual noise $[. .$.$] and focus on a lone visual message"$ (Dontigney 2019).

What is more, such a peaceful form creates a more relaxed cognitive environment for the perceiver in which he may be more eager to engage in a playful communication mode. As a result, the persuasive aspect of such ads gains more strength because playfulness may conduce to increased liking for the ad, product or brand (Gulas and Weinberger 2006). The analysis herein conducted has shown that advertising messages do not need to be complex in order to be humorous, which makes one ponder over whether or not such minimalistic ads can potentially fare better than complex advertising messages.

Though it can be seen as a limitation that the study relied on the advertising material produced between 2007 and 2015, on the grounds that the examples are not the latest ones, the dataset was selected so as to illustrate the humorous potential of simplicity in advertising. Thus, the aim of the paper was to show one of the possible trends in general. The dynamic nature of advertising cannot be gainsaid and more pieces of research referring to new examples should follow the one adumbrated herein in order to confirm (or disprove) the existence of minimalistic trends in advertising strategies. Another possible avenue for further research would be to extend the dataset to incorporate both simple and complex press advertisements and then compare ad ratings in terms of comprehension or funniness, for instance. In the light of the foregoing, one can conclude that the power of simplicity may constitute a promising starting point as regards future analysis of advertising discourse, as it will offer a valuable contribution to the study of both advertising language and humour structures, hence possibly suggesting that there may still be so much about simple forms we do not realise. 


\section{Bibliography}

Abadi-Nagy Z. (2001): Minimalism vs. Postmodernism in Contemporary American Fiction, "Akadémia i Kiadó” 28, 1, pp. 129-143.

Bateman J.A. (2008): Multimodality and Genre: A Foundation for the Systematic Analysis of Multimodal Documents, New York.

Berger A.A. (2011): Ads, Fads, and Consumer Culture. Advertising's Impact on American Character and Society, Plymouth.

Bergström B. (2009): Komunikacja wizualna, transl. J. Tarnawska, Warszawa.

Botha M. (2015): Why minimalism matters: radical quantity and there presentation of immanence, “Textual Practice" 29, 4, pp. 745-772.

Chłopicki W., Brzozowska D. (2017): A foreword on humorous discourse, [in:] Humorous Discourse, W. Chłopicki, D. Brzozowska (eds.), Boston-Berlin, pp. 1-7.

Burgess J.A. (1997): What is Minimalism about Truth?, "Analysis" 57, 4, pp. 259-267.

Chen Q., Jiang G. (2018): Why are you amused: Unveiling multimodal humour from the prototype theoretical perspective, "European Journal of Humour Research" 6, 1, pp. 62-84.

Dontigney E. (2019): Minimalism in Advertising, "Small Business - Chron.com", http://smallbusiness. chron.com/minimalism-advertising-69504.html (accessed: 02.09.2019).

Dynel M. (2013): Humorous phenomena in dramatic discourse, "The European Journal of Humor Research" 1, s. 22-60.

Giora R. (1991): On the cognitive aspects of the joke, "Journal of Pragmatics" 16, pp. 465-485.

Gulas C.S., Weinberger M.G. (2006): Humor in Advertising, Armonk-New York-London.

Inbar O., Tractinsky N., Meyer J. (2007): Minimalism in information visualization: attitudes towards maximizing the data-ink ratio, [in:] Proceedings of the 14th European conference on Cognitive ergonomics: invent! explore!, W.P. Brinkman, D.H. Ham, B.L.W. Wong (eds.), pp. 185-188.

Karaśkiewicz A. (2013): Tekst, obraz i ich wzajemne relacje $w$ tworzeniu przekazu na przykładzie ulotek reklamowych, "Media - Kultura - Społeczeństwo" 7-8, pp. 65-74.

Kawka M. (2016): Dyskurs Multimodalny — Nowa Kategoria Badawcza?, "Zeszyty Prasoznawcze" 59, 2, pp. 294-303.

Kress G., van Leeuven T. (1996): Reading Images. The Grammar of Visual Design, London.

Krikmann A. (2009): On the Similarity and Distinguishability of Humour and Figurative Speech, “TRAMES"13, 63/58, pp. 14-40.

Kumar A. (2008):Visual Communication: A Media for Research and Planning, New Delhi.

Macleod D. (2008): Hitler vs. Chaplin for Hut Weber Hats - The Inspiration Room, http://theinspiration room.com/daily/2008/hitler-vs-chaplin-for-hut-weber-hats/ (accessed: 19.09.2019).

Maćkiewicz J. (2017): Badanie mediów multimodalnych - multimodalne badanie mediów, "Studia Medioznawcze" 2, 69, pp. 33-42.

Margariti K., Boutsouki Ch., Hatzithomas L., Zotos Y. (2017): A Typology of Minimalism in Advertising, [in:] Advances in Advertising Research VIII. European Advertising Academy, V. Zabkar, M. Eisend (eds.), Wiesbaden, pp. 1-15.

Nerhardt G. (1976): Operationalization of Incongruity in Humour Research: A Critique and Suggestions, [in:] It's a Funny Thing, Humour: Proceedings of The International Conference on Humour and Laughter, A.J. Chapman, H.C. Foot (eds.), Oxford, pp. 46-51.

O’Donohoe S. (2001): Living with ambivalence - Attitudes to advertising in postmodern times, "Marketing Theories Articles" 1, 1, pp. 91-108.

Pérez-Sobrino P. (2017): Multimodal Metaphor and Metonymy in Advertising, Amsterdam-Philadelphia.

Raskin V. (1985): Semantic Mechanisms of Humor, Dordrecht.

Stevanovich V. (2013): A Reading of Interpretative Models of Minimalism Architecture, "METU Journal of the Faculty of Architecture" 30, 2, pp. 181-194. 
Stöckl H. (2009): Beyond Depicting. Language-Image-Links in the Service of Advertising, "Arbeiten aus Anglistik und Amerikanistik" 34, 1, pp. 3-28.

Stwora A. (2019): Less words, please! Visual ads as evocative rhetorical constructs of the modern age, [in:] Cognition in Context - New Insights into Language, Culture and the Mind, E. Bernárdez, J. Jabłońska-Hood, K. Stadnik (eds.), Berlin, pp. 57-69.

Suls J. (1976): Cognitive and Disparagement Theories of Humour: A Theoretical and Empirical Synthesis, [in:] It's a Funny Thing, Humour: Proceedings of The International Conference on Humour and Laughter, A.J. Chapman, H.C. Foot (eds.), Oxford, pp. 41-45.

Tanaka K. (1996): Advertising language: a pragmatic approach to advertisements in Britain and Japan, London-New York.

Tornetta S., Fox T. i Blackbird, J. (2009): Color sells: How the psychology of color influences consumers, Delaware.

VanEenoo C. (2011): Minimalism in Art and Design: Concept, influences, implications and perspectives, "Journal of Fine and Studio Art" 2, 1, pp. 7-12.

\section{Advertising material analysed:}

Aspirin Bayer, Cafiaspirin - Dad. Advertising agency: BBDO, November 2012. https://www.adsoft heworld.com/media/print/aspirin_bayer_cafiaspirin_dad (accessed: 03.09.2019).

Bank Forum, Commerzbank - Chaos. Advertising agency: Ogilvy, March 2010. https://www.adsoft heworld.com/media/print/bank_forum_commerzbank_chaos (accessed: 03.09.2019).

Bosch - The fly. Advertising agency: Jung von Matt, December 2007. https://www.adsoftheworld.com/ media/print/bosch_the_fly (accessed: 03.09.2019).

Gomby — Monday. Advertising agency: DDB, July 2015. https://www.adsoftheworld.com/media/print/ gomby_monday (accessed: 03.09.2019).

Hut Weber - Hitler vs. Chaplin. Advertising agency: Serviceplan, March 2008. https://www.adsoftheworld.com/media/print/hut_weber_hitler_vs_chaplin (accessed: 03.09.2019).

KISS FM - Father. Advertising agency: Garcia + Robles, January 2007. https://www.adsoftheworld. com/media/print/kiss_fm_father (accessed: 03.09.2019).

\section{Do humoru przez prostotę? O minimalistycznych, a zarazem humorystycznych multimodalnych reklamach prasowych}

Abstrakt

Celem niniejszego artykułu jest analiza wybranych przykładów minimalistycznych, multimodalnych reklam prasowych, które mają ukazać, że relatywnie prosta forma może skutecznie przekazywać treści o zabarwieniu humorystycznym. Autorka zaczyna dyskusję od kilku ogólnych uwag na temat multimodalności i wyjaśnienia zagadnienia minimalizmu, który sytuuje w kontekście analizy dyskursu reklamy. Następnie przywołuje krótki opis teorii rozwiązywania niespójności, która ma przybliżyć czytelnikowi zjawisko humoru. Bazując na wybranych minimalistycznych reklamach prasowych wpisujących się w wyżej wspomnianą teorię humoru, autorka dokonuje analizy jakościowej kilku reklam, by ukazać, że prostota wcale nie czyni dyskursu reklamy nudnym. Przeciwnie, pomaga ona odbiorcom skupić się na przekazie oraz docenić kreatywność i humor mogące płynąć z minimalistycznych reklam.

Słowa kluczowe: reklama minimalistyczna, badania nad humorem, dyskurs reklamy, prostota w języku. 